\title{
Assessment of Crushed Glass as a Medium for Rapid Rate Filtration
}

\author{
J.O. Jeje $\mathrm{e}^{*}$, O. Hassan ${ }^{1}$ and O.A. Ogundipe ${ }^{1}$
}

\author{
${ }^{1}$ Department of Civil Engineering, Obafemi Awolowo University, Ile-Ife \\ *Corresponding author
}

\begin{abstract}
This study was carried out to assess the potential of crushed glass as a filter medium in high rate filtration. Waste glass collected from a glass manufacturing industry was crushed using hammer mill and sorted into different particle sizes $(0.300 \mathrm{~mm}, 0.425$ $\mathrm{mm}, 0.550 \mathrm{~mm}, 1.18 \mathrm{~mm}$ and $2.36 \mathrm{~mm}$ ). The gravel layer was between $2.36 \mathrm{~mm}$ to $4.75 \mathrm{~mm}$. The glass were arranged in layers and used as the filter bed for the water filtration process. The depth of each medium was set at $800 \mathrm{~mm}$ with a constant flow rate of $0.0275 \mathrm{l} / \mathrm{s}$, and the experimental run of 4 hours. The flow rate, turbidity and head at the ports were monitored at every 30 minutes interval. Glass shows a tremendous decrease in filtration rate with time compared to sand and also a higher headloss developed. At 2.5 hours, glass had attained a turbidity of $0 \mathrm{NTU}$ while sand at 3.5 hours. The results show an increase in filtration efficiency in glass compared to sand which suggests that crushed glass could be used conveniently as a medium for rate of filtration.
\end{abstract}

Keywords-Crushed glass, high rate filtration, filter media, surface water and hammer mill.

\section{INTRODUCTION}

Water is one of the most abundant compounds found in nature, covering approximately three-fourths of the earth. In spite of this apparent abundance, several factors serve to limit the amount of water available for human use (Boveet al., 2015). Though, water occupies about $71 \%$ of the earth's surface over $97 \%$ of the total water supply is contained in the oceans and other saline bodies of water and is not readily useable for most purposes. Thus for general livelihood and the support of their varied technical and agricultural activities, humans must depend on the remaining $0.62 \%$ found in fresh water lakes, rivers and ground water supplies (Todd, 2011; Hucket al.,2010). The World Health Organization (WHO) has however set up standards for potable water. To meet these standards, the raw water gotten from nature will have to undergo a series of treatment processes. A typical treatment plant for surface water is made up of aeration unit, coagulation unit, sedimentation unit, filtration unit, disinfection and then distribution unit. Water which has passed through the coagulation unit and then settled, is invariably passed through a filter before it is disinfected and supplied to users. The most common filter used in conventional treatment plants all over the world is made up of silica sand underlain by gravel, and it filters water at rates ranging from 80 to 250 litres per minute per square metre of the surface area of the filter bed (Ogedengbe, 1985).

Rapid filtration generally implies a process, which includes coagulation, flocculation, clarification and disinfection (McGhee, 1991). The rapid filters are usually constructed as open-top, free-surface units and less frequently as in-line pressure units(Matilainenet al., 2010). The rapid sand filters utilize a bed of silica sand ranging from 0.6 to $0.75 \mathrm{~m}$ in depth. Sizes may range from $0.35 \mathrm{~mm}$ or even larger, with effective sizes of 0.45 to $0.55 \mathrm{~mm}$. a uniformity coefficient of 1.65 is commonly specified (Korkosz et al., 2012).

Filtration rates following flocculation and sedimentation are in range of 1.4 to $6.81 / \mathrm{m}^{2} \mathrm{~s}$, with $3.41 / \mathrm{m}^{2} \mathrm{~s}$ normally the maximum design value(Boveet al., 2015). Because of the higher filtration rates, the area requirement of a rapid filtration plant is about $20 \%$ of that required for the slow sand filters, although the latter usually do not require pretreatment of the raw water (Korkosz et al., 2012).

The idea of using crushed glass as filter medium is a new development. Glass scraps which are more are less "wastes" from glass industries are available in large quantities and can be processed to serve a useful purpose in water filtration. Bryant et al. (2011) has established that with the use of recycled crushed glass, the quality of water was improved. Hence in furtherance of research using this filter medium, a confirmation on whether these qualities will be achieved with glass from our local industries was made the subject of this study.

\subsection{Description of the Study Area}

Effluent from the sedimentation tanks of the Opa Water treatment plant in Obafemi Awolowo University, Ile -Ife was siphoned and used as the influent water sample. It was ensured that the water was not contaminated or polluted with any other materials other than the state it was before being collected from the weir. 
II. MATERIALS AND METHODS

The materials that were used for the project include the filter media (crushed glass and silica sand), Polyvinyl chloride (PVC) pipes of 4 inches diameter for the construction of the pilot filter unit, pipes and appurtenances of $3 / 4$ inches and water (effluent from sedimentation tank).

The silica sand used for the filtration process was obtained from the Opa Water treatment plant. This particular sand material is used as the filter bed in treating water supplied to the university community. The silica sand obtained was in three batches and arranged in increasing order of coarseness and sizes.

Crushed glass materialwas obtained from TSG industry Olodo, Ibadan. The glass obtained was post-industrial plate glass scrap. This was chosen because it is completely free of the potential organic and inorganic contamination that can be present in post-consumer container glass.

The following equipment and apparatus were procured for the filtration process colorimeter, water sample bottles, measuring cylinder, stop watch and manometer.

The turbidity of the influent and effluent water samples was measured using a colorimeter (JENWAY, 6501).

According to Matilainenet al.(2010), the values obtained from the colorimeter used can be converted to NTU readings using the equation

$Y=275.5+2.79 x$

where $\mathrm{x}=$ colorimeter reading; $\mathrm{Y}=$ turbidity in NTU

In the absence of a pressure gauge for taking pressure reading a manometer board was constructed. The manometer board was constructed from plywood, with supports made from wooden members. It consisted of three manometer tubes, the tubes were not more than 2.0 $\mathrm{mm}$ in diameter and about $1.5 \mathrm{~m}$ long. The manometer board was provided with graduated scale for monitoring the headloss developed in the filter bed.

Pilot filter unit made from a circular cross polyvinyl chloride pipe with 4 inches diameter and cross-sectional area of $8,108 \mathrm{~mm}^{2}$ was used. The head of water above the filter bed was kept constant by the overflow mechanism. This was done by making a hole of about $10.0 \mathrm{~mm}$ in the pipe which prevented water rising beyond a particular level. An underdrain was provided at the bottom of the pilot unit to support the medium and to allow the effluent from the unit pass to the effluent storage unit. The filter unit was supported at the base and braced properly for stability and possible leakage. Along the height of the pipe were installed three manometer ports to record the headloss at different level of the bed (Boveet al., 2015).
The main activities or operation include sieve analysis, determination of specific gravity of the materials, arrangement of the media into the unit, charging of filter, experimental procedure and data collection.

The American Standard for Testing and Materials (ASTM) sieve sizes were used. The following sieve sizes were used for the analysis, sieve numbers 8.0, 16.0, 20.0, 40.0 and 50.0 with opening diameters $2.36 \mathrm{~mm}, 1.18 \mathrm{~mm}$, $0.85 \mathrm{~mm}, 0.425 \mathrm{~mm}$ and $0.30 \mathrm{~mm}$ respectively.

Horan and Lowe (2007) states that for the determination of oversize and undersize aggregates and especially for research work on aggregate grading, additional sieve sizes are required. The results of the sieve analysis were used to determine the effective size and uniformity coefficient of the materials.

The glass material procured from the glass industry was crushed, screened and sieved to meet the specification required for the filter media. The glass material was crushed using a crushing machine into different particle sizes. Glass particles extremely larger than the required size were re-crushed. The sand procured was washed thoroughly and dried before sieving.

The system was set-up as shown systematically in Figure 1 , and was tested for leakages. The crushed glass particles were arranged into the vertical circular pipe with large particle sizes at the bottom $(1.18-2.36 \mathrm{~mm})$, followed by $0.425-0.850 \mathrm{~mm}$ sizes and then $0.30 \mathrm{~mm}$ at the uppermost layer. Particle sizes ranging from $2.36 \mathrm{~mm}-$ $4.75 \mathrm{~mm}$ was used as the gravel layer just above the underdrain (Soyeret al., 2010).

Clean water was then introduced from the top to remove all air bubbles in the medium and ensure proper gradation. The same procedure was carried out for sand. This was done in preparation of experimental runs.

Experimental procedure was done by opening the influent valve to allow the influent to be at the desired and predetermined flow rate. The effluent control valve was then opened to allow flow from the filter bed. Water level above the medium was maintained to avoid overflow which was done by the provision of holes at the side of the pipe. The filtration rate, turbidity and head at the ports were monitored at 30 minutes interval, with the runs lasting for 4 hours using a constant flow and variable head method (Lee, 2014).

The same procedure was carried out for sand with the depth of each medium set at $800 \mathrm{~mm}$ including the gravel layer. The effluent valve was shut at the end of the experimental runs and then the influent, leaving the filter under a full head of water. 


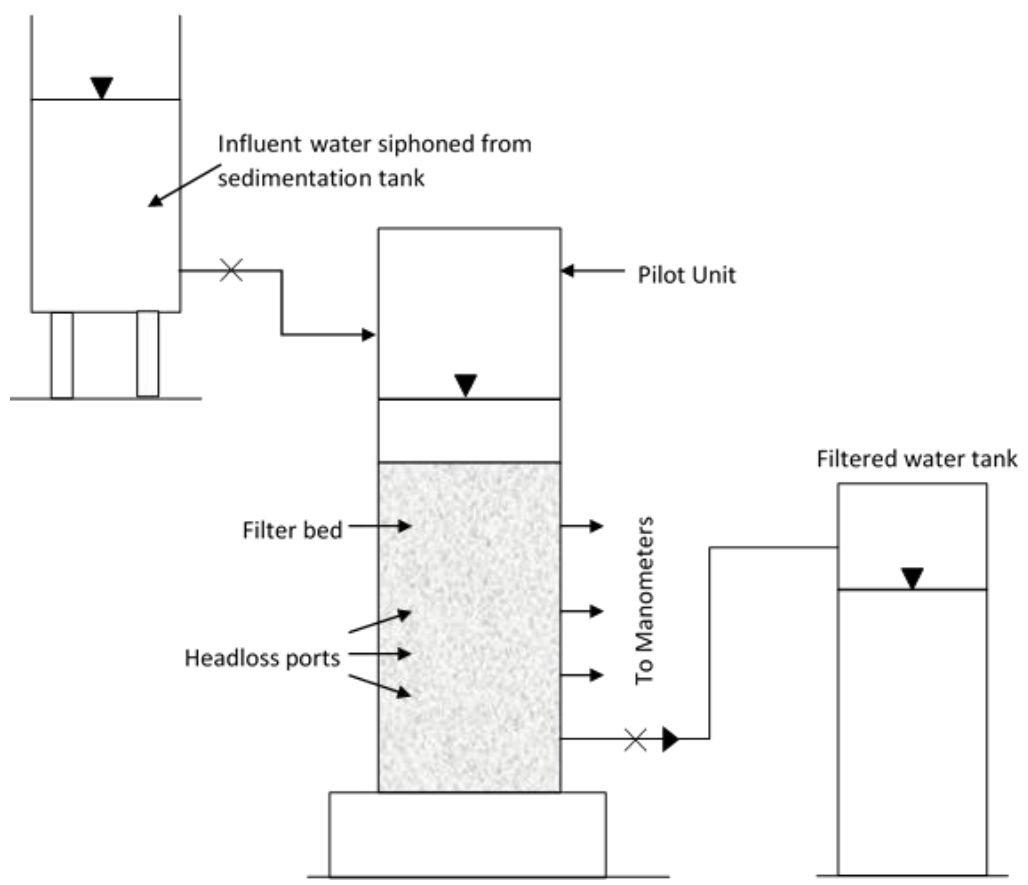

Fig.2.1: Schematic layout of filter unit

\section{RESULTS AND DISCUSSION}

The physical properties of the filter media are shown in Table 1. The grading curve of the crushed glass and sand media extends over a limited range. This shows that the crushed glass is less dense than sand but denser than water, therefore will not float in water.

Table.1: Physical properties offilter media

\begin{tabular}{lll}
\hline Physical properties & Sand & Glass \\
\hline Effective size $\left(\mathbf{D}_{\mathbf{1 0}}\right)(\mathbf{m m})$ & 0.357 & 0.671 \\
Uniformity coefficient $\left(\mathbf{U}_{\mathbf{c}}\right)$ & 1.5 & 1.906 \\
Specific gravity $\left(\mathbf{G}_{\mathbf{s}}\right)$ & 2.61 & 2.53 \\
\hline
\end{tabular}

\subsection{Headloss and Filtration Rate}

The headloss build-up across the filter beds was measured in centimetres of water developed above the bed. The variation of headloss with time between the two media is shown in Table 2. The effluent from the underdrain was noticed to start flowing at 2 minutes and 2.57 minutes for sand and glass respectively after the influent value was opened. The initial headloss developed at this time in each case was also recorded to be $8.5 \mathrm{~cm}$ and $11.5 \mathrm{~cm}$ respectively. The variation of headloss between the two media with time is shown in Figure 2, there is an increase in water headloss developed across the bed with time and it is fairly uniform. It can be seen from this figure that glass developed a higher headloss than sand within the same filtration time. This was due probably to the rapid clogging of the glass medium which can be seen as a result of relatively smaller interstitial spaces in comparis on with sand (Horan and Lowe, 2007).

The flow rate from the influent valve was set at a constant value of $0.0275 \mathrm{l} / \mathrm{s}$ for the two filter media throughout the experimental run. The variation in filtration rate with time is shown in Table 2 and Figure 3. The filtration rate of both media decreases rapidly with time. The deciding factor for such behaviour is the particle size of the glass medium which on average has less rounded edges than sand (Horan and Lowe, 2007). Hence, it can be declared that the reason for filtration rate decline in the glass medium being higher was due to its more efficient trapping of smaller turbid particles (Lee,2014;Bryant et al.,2011).

Table.2: Headloss and filtration rate across the bed with time

\begin{tabular}{llllllllll}
\hline & $\begin{array}{l}\text { Time } \\
\text { (hrs) }\end{array}$ & $\mathbf{0 . 5}$ & $\mathbf{1 . 0}$ & $\mathbf{1 . 5}$ & $\mathbf{2 . 0}$ & $\mathbf{2 . 5}$ & $\mathbf{3 . 0}$ & $\mathbf{3 . 5}$ & $\mathbf{4 . 0}$ \\
\hline Headloss (cm) & Glass & 12.8 & 14.2 & 15.5 & 17.2 & 19.0 & 21.0 & 22.2 & 23.5 \\
\cline { 2 - 10 } & Sand & 9.6 & 10.9 & 11.8 & 13.0 & 14.3 & 15.3 & 16.5 & 18.0 \\
\hline Filtration rate & Glass & 2.812 & 2.603 & 2.43 & 2.22 & 2.109 & 1.974 & 1.739 & 1.517 \\
\cline { 2 - 9 }$\left(\mathbf{l} / \mathbf{m}^{2} . \mathbf{s}\right)$ & Sand & 3.195 & 2.973 & 2.837 & 2.825 & 2.738 & 2.677 & 2.541 & 2.442 \\
\hline
\end{tabular}




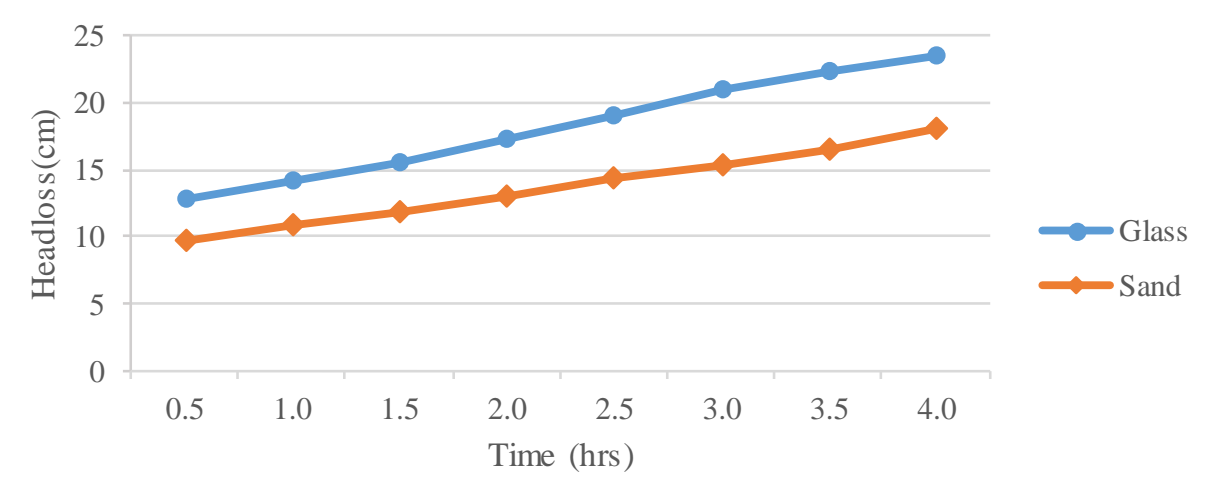

Fig.3.2: Variation of headloss across the beds with time

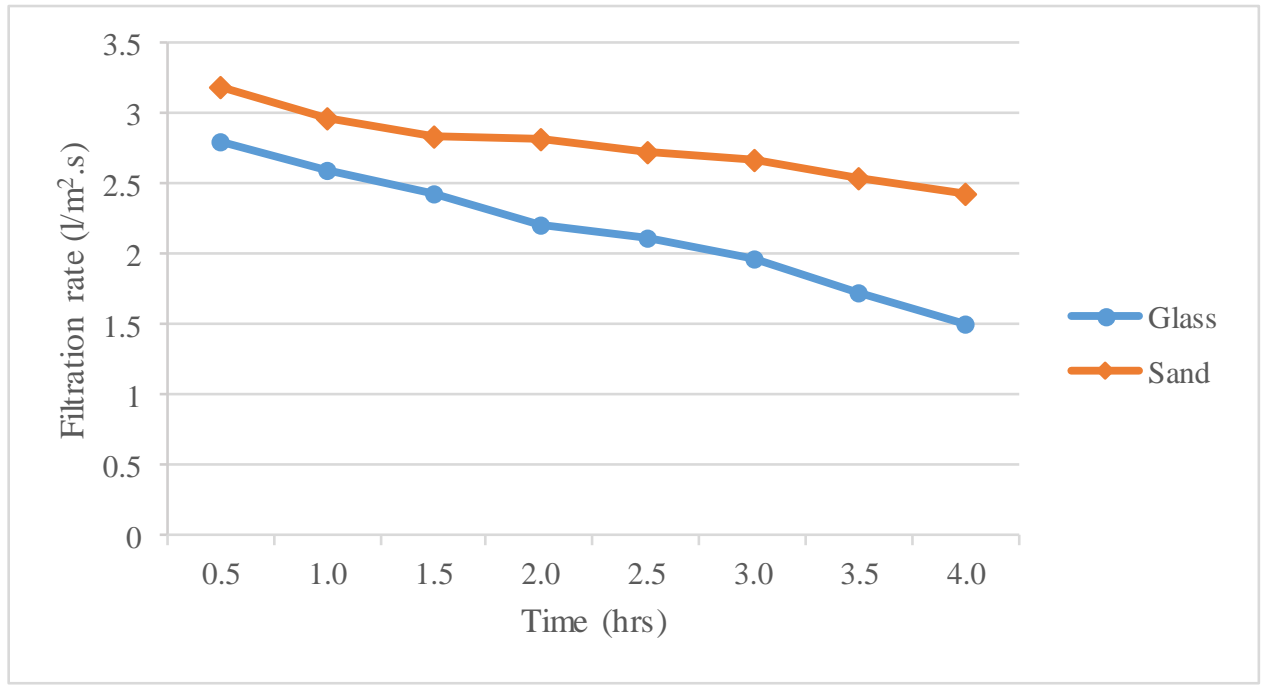

Fig.3.3: Variation offiltration rate with time between the filter beds

\subsection{Turbidity}

According to Ogedengbe (1985), a filtration run would normally be terminated when, either the headloss across the bed becomes excessive or the quality of the water produced declines to an unacceptable level. Either of these two conditions could occur first.

The results of turbidity readings in NTU are shown in Table 3 and the plot in Figure 4. This shows correlation and variation in turbidity for the two media (glass and sand) at different points in time. The values gotten from the colorimeter were converted to NTU using the standard expression in Equation (1). It was observed to be equal for the first hour of filtration after which a sharp decline was observed in glass turbidity. At exactly $2 \mathrm{hrs}$ filtration time both media attain equal value with sand afterwards having a constant value up to the 3 hour. Finally, at $3.5-$ 4 hours filtration time both media recorded 0 NTU. The result shows that finer particles were removed in the glass filter more efficiently, reflected by decrease in NTU.

Table.3: Converted colorimeter readings

\begin{tabular}{ccccccccccc}
\hline & Time (hrs) & 0.0 & 0.5 & 1.0 & 1.5 & 2.0 & 2.5 & 3.0 & 3.5 & 4.0 \\
\hline \multirow{2}{*}{ Colorimeter readings } & Glass & 96 & 97 & 97 & 98 & 98 & 99 & 99 & 100 & 100 \\
& Sand & 96 & 97 & 97 & 97 & 98 & 98 & 98 & 99 & 99 \\
\multirow{2}{*}{ Turbidity (NTU) } & Glass & 7.66 & 4.87 & 4.87 & 2.08 & 2.08 & 0.00 & 0.00 & 0.00 & 0.00 \\
& Sand & 7.66 & 4.87 & 4.87 & 4.87 & 2.08 & 2.08 & 2.08 & 0.00 & 0.00 \\
\hline
\end{tabular}




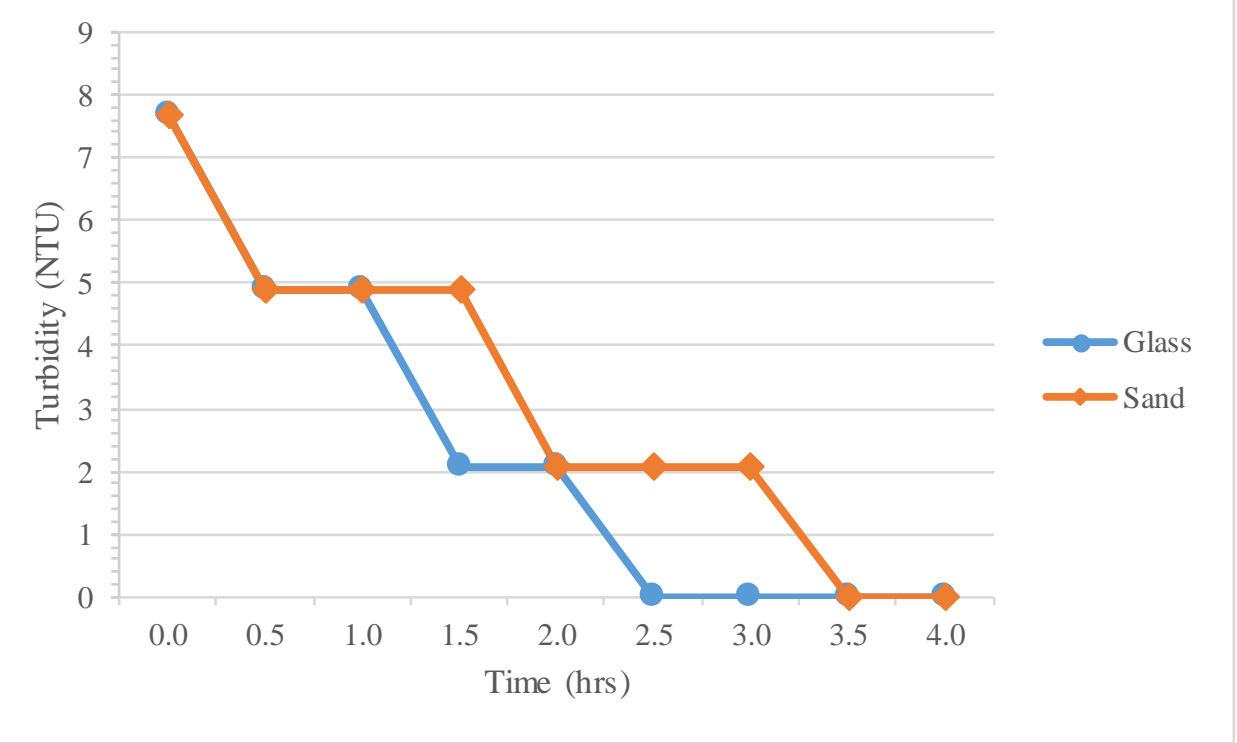

Fig.3.4: Variation of turbidity with time between the filter effluents

\section{CONCLUSION}

Based on the results of the study, it can be stated that crushed glass is capable of being used as a medium for water filtration. The following conclusions were made: glass is potentially useful for water filtration, with improved water quality through longer filtration time, filtration rate is les with a higher head loss build up with glass, due to the crystal clear nature of glass, less water was required to clean the filter bed before the start of experimental run and glass is less dense than sand, therefore, less medium by weight is required when using crushed glass as filter medium.

\section{REFERENCES}

[1] Clean Washington Centre (1998). Evaluation of recycled crushed glass sand media for high-rate sand filtration: A division of the Pacific North West Economic Region (PNWER), Seattle, Washington.

[2] McGhee, T.J. (1991). Water Supply and Sewerage, 6th edition, McGraw-Hill Inc. Singapore.

[3] Ogedengbe, M.O. (1985). 'Water filtration using locally available sand', Journal of Australian Water and Wastewater Association, Vol. 9, pp $20-23$.

[4] Korkosz, Al.; Ptaszynska, A.; Hanel, A.; Niewiadomski, M.; Hupka, J. (2012) Cullet as filter medium for swimming pool water treatment. Physicochemical Problems of Mineral Processing, 48(1): 295-301.

[5] Todd, D.K. (2010). The Water Encyclopedia, 1st edition, The Maple Press Company, New York.

[6] Horan, N.J. and Lowe, M. (2007) Full-scale trials of recycled glass as tertiary filter medium for wastewater treatment. Water Res., 41(1): 253-259.

[7] Huck, P.M., Coffey, B.M., and O'Melia, C.R. 2011. Filter operation effects on pathogen passage.
American Water Works Association Research Foundation, Denver, Colo.

[8] Soyer, E.; Akgiray, O.; Eldem, N.O.; Saatci, A.M. (2010) Crushed recycled glass as a filter medium and comparison with silica sand. Clean - Soil, Air, Water, 38(10): 927-935.

[9] Lee, C.T. (2014) Preparation of Spherical foamed body with function of media waste water treatment by using waste LCD glass. J. Ind. Eng. Chem 20(5) $3089-3095$

[10] Matilainen, A.; Vepsäläinen, M.; Sillanpää, M. (2010) Natural organic matter removal bycoagulation during drinking water treatment: a review. Advances in Colloid and Interface Sci., 159(2): 189-197

[11] Bryant, R.; Sadar, M.; Pernitsky, D.J. (2011) Online Sensors for Monitoring and Controlling Coagulation and Filtration, in Operational Control of Coagulation and Filtration Processes - Manual of Water Supply Practices, M37, 3rd ed.; American Water Works Association (AWWA).

[12] Bove, J., Arbat, G., Dura-Rose, M., Pujol, T. (2015) Pressure drop cross Sand and Resycled Glass Media used in Micro Irrigation Filters Biosystem Eng., 135: $55-63$ 